\section{Audrey Bellesoeur Ludivine Chalumeau-Lemoine François Blot}

\title{
Excavated pneumonia: an unusual suspect
}

Received: 28 February 2013

Accepted: 2 March 2013

Published online: 10 April 2013

(C) Springer-Verlag Berlin Heidelberg and ESICM 2013

Patients' consent and permission to publish: written consent was obtained from the next of kin of the patient.

A. Bellesoeur · L. Chalumeau-Lemoine $(\varpi) \cdot$ F. Blot

Service de Réanimation médico-chirurgicale, Institut Gustave

Roussy, 114 rue Edouard Vaillant, 94805 Villejuif, France

e-mail: ludivine.chalumeau-lemoine@igr.fr

Tel.: +33-1-52116281

Fax: +33-1-52114226

A 23-year-old man was diagnosed with acute myeloid leukaemia. He received induction chemotherapy and antimicrobial prophylaxis with broad spectrum antibiotherapy and caspofungin.

As he presented acute respiratory distress and febrile neutropenia, pulmonary CT was performed and revealed a right upper lobe excavated nodule surrounded by groundglass opacities (Fig. 1a).

Caspofungin was switched for voriconazole and liposomal amphotericin B.

On the control CT (day 33), pulmonary infiltrate excavation and ground-glass opacities worsened and a second nodule appeared on left upper lobe.

Patient condition worsened and he died in a refractory hypoxemia context (day 52).

Bronchial aspiration and lung biopsy revealed creamcolored cotton-like colonies on culture. Further characterization identified a septated hyphae fungus (Fig. 1b), namely Hormographiella aspergillata.

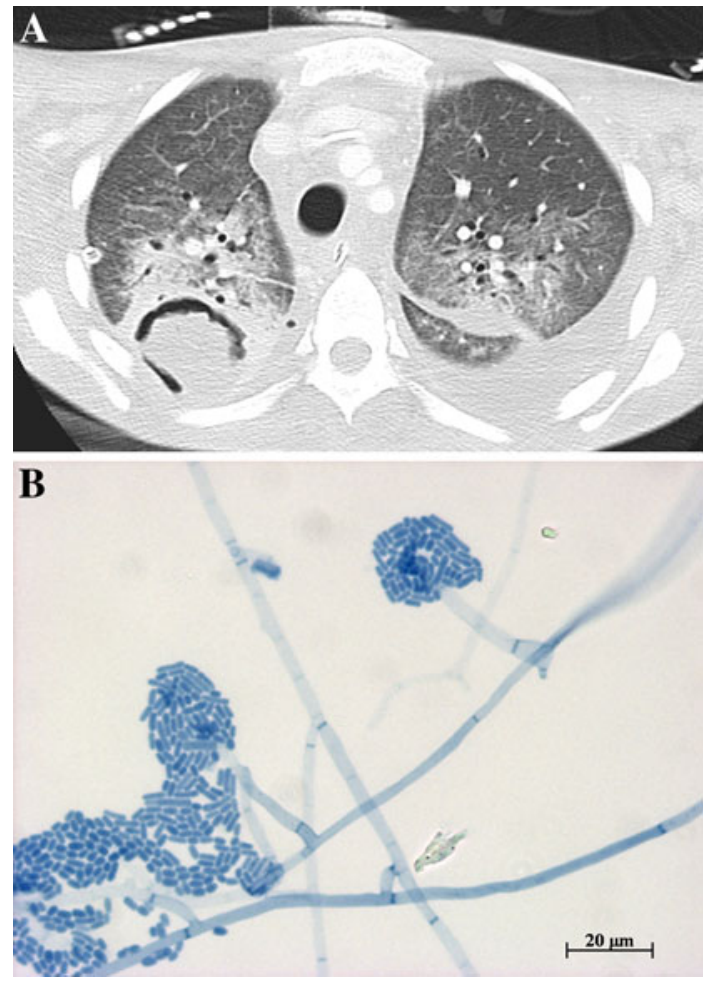

Fig. 1 a pulmonary CT scan (day 22) showing pulmonary infiltrate with ground-glass opacities and excavated nodule in the right upper lobe. b microscopic morphology of $H$. aspergillata (anamorph Coprinopsis cinerea basidiomycetes): hyaline septated hyphae with short and broad conidiophores, from which arise cylindrical arthroconidia in clusters or in irregular groups

H. aspergillata has been rarely reported as a source of human infections but seems to be emerging [1-3]. It proved to be invasive, a source of high mortality and hard to diagnose (aspergillosis-like presentation, unknown 
epidemiology, highly skilled microbiologists required). Besides, it presents a peculiar antifungal susceptibility: good susceptibility to azoles (except fluconazole and flucytosine) and to voriconazole (MIC $<2 \mu \mathrm{g} / \mathrm{mL}$ ), amphotericin B variable activity $(0.5-4 \mu \mathrm{g} / \mathrm{mL})$ while echinocandins are ineffective $(>4 \mu \mathrm{g} / \mathrm{mL})$ [1-5].
Physicians should be aware that empiric antifungal therapies modify fungal epidemiology and then have an impact on therapeutic strategies in neutropenic patients.

Conflicts of interest The authors have not disclosed any potential conflicts of interest.

\section{References}

1. Lagrou K, Massonet C, Theunissen K, Meersseman W, Lontie M, Verbeken E, Van Eldere J, Maertens J (2005) Fatal pulmonary infection in a leukaemic patient caused by Hormographiella aspergillata. J Med Microbiol 54:685-688

2. Suarez F, Olivier G, Garcia-Hermoso D, Randriamalala E, Ghez D, Bruneau J, Kauffmann-Lacroix C, Bougnoux ME, Lortholary O (2011) Breakthrough Hormographiella aspergillata infections arising in neutropenic patients treated empirically with caspofungin. J Clin Microbiol 49:461-465
3. Conen A, Weisser M, Hohler D, Frei R, 5. Abuali M, Posada R, Del Toro G, Roman Stern M (2011) Hormographiella aspergillata: an emerging mould in acute leukaemia patients? Clin Microbiol Infect 17:273-277

4. Vermeij PE, van Kasteren M, van de Nes J, de Hoog GS, de Pauw BE, Meis JF (1997) Fatal pulmonary infection caused by basidomycete Hormographiella aspergillata. J Clin Microbiol 35:2675-2678
E, Ramani R, Chaturvedi S, Chaturvedi V, LaBombardi VJ (2009) Rhizomucor variabilis var. regularior and Hormographiella aspergillata infections in a leukemic bone marrow transplant recipient with refractory neutropenia. J Clin Microbiol 47:4176-4179 